\section{Why Internationalize Education?}

\section{Robert Coelen}

Robert Coelen is Professor of Internationalisation of Higher Education at Stenden University of Applied Sciences, The Netherlands, and can be contacted at robert.coelen@stenden.com.

$\mathrm{D}$ espite a long history of internationalization activities at the institutional level and at times at the program level, many faculty members still struggle with the imperative to internationalize their classes or programs. Given the learning outcomes of internationalization-which should include intercultural effectiveness, among others-and given the tremendous forces of globalization that include significant migration (which, according to UN data, involved 2IO million people in 20I0), it is hard to understand why anyone would still question the need for this response by those directly responsible for delivering education.

\section{Changing Global Forces}

Since the turn of the century, we have been witnessing unprecedented changes in global business. Until about that time, there had been little variation in the geographic location of the Fortune Global 500 companies, and about 95 percent of them were located in so-called developed regions. By 2010, the proportion in developed regions had gone down to 83 percent, and in 2014 to 69 percent. This trend is expected to continue with a further decline to 54 percent in 2025. This statistic is a clear indicator of the shift toward an upsurge of "non-traditional" countries with significant business activity.

McKinsey \& Company have shown in various reports how the global distribution of the middle class is likely to change. In 2030, it is expected that some 66 percent of the global middle class will live in the Asia-Pacific region. Countries such as India and China, and others in Asia, will race ahead while the "traditional" regions-such as Europe and North America-will see significant proportional declines. By 2030 , the aircraft manufacturing industry predicts a significant increase in regular passenger air travel in and to these non-traditional countries-with destinations within China experiencing the greatest increase. These increases can be seen as resulting from enhanced business activity and more leisure travel by the growing middle classes.

Another major global force is that of urbanization and the development of a much-enhanced network of significant global urban centers. Air travel during the last century mostly took place between the well-established major capitals of the world, but this is now undergoing dramatic change in two ways. First, more and more airports are now located in cities that are not capitals, either established de novo or by updating disused or former military airports. Secondly, and possibly more significantly, their status has been promoted to that of international gateways, often as a result of budget airlines seeking out better value connections. Such new connections not only drive leisure travel upwards, but also increase business mobility and that of students. Newly connected urban centers, by virtue of the nature of the urban workforce, also create concentrations of knowledge societies in this new global network. Predictions are that 440 emerging cities in this global network will contribute 47 percent of total global economic growth by 2025 , and will have I billion new consumers. This network will be a large part of the playing field of the professionals of the future and requires such professionals to be internationally aware and interculturally effective.

Apart from the ability to fund leisure travel, the middle classes can also be identified as wanting a good education for their children, in addition to housing, health care, and pensions. One would, therefore, also expect to see an upsurge in demand for higher education.

\section{It is likely that in such a future our grad- uates will work with people from, or in, another culture.}

Indeed, Organisation for Economic Co-operation and Development (OECD) data show that, on the basis of current trends, half the number of projected graduates in 2030 (aged 25-34) will come from China and India alone, with Europe and the United States together accounting for less than 25 percent. It is likely that, in such a future, our graduates will work with people from, or in, another culture. Indeed, even today many companies in Europe have to resort to recruiting graduates from outside their home country due to a lack of suitable domestic graduates, thereby already creating significantly intercultural workplaces.

\section{THE IMPACT OF TECHNOLOGY}

A fourth major global force is the advancement of technology. In a recent survey of education experts carried out by the World Innovation Summit for Education (WISE), 50 percent of those polled predicted that by 2030 the most important source of knowledge will be available as online content. This statistic is not surprising given the huge increase in information on the Internet and the increasing ease with which this can be published. Learning materials that are 
available in an electronic format are easily distributed and adapted, making this an attractive proposition for ongoing development, and also for creating blended programs with online course provision alongside limited periods of oncampus attendance.

Another effect of technology that is relevant for this discussion is the phenomenon described by Carl Benedikt Frey and Michael A. Osborne, namely that of job polarization. They note that, with current developments in computer technology, significant shifts could be expected to occur in the nature of jobs in twenty years or so, with some jobs being performed entirely by computers. However, many jobs would not fall into this category: the type of jobs that would be least likely to be replaced by computer technology include jobs in which heuristics, human social interaction, working in cramped spaces, and innovation play a significant role.

All the global changes combined create a future in which intercultural contact will be the norm, rather than the exception. Thus, it follows that the skills, attitudes, and knowledge required to be interculturally effective should become a more significant part of a student's development than they have been heretofore.

\section{Higher Education's Response}

The congruence of a number of predictions about global development-including the expansion of a globally interconnected urban center network, a shift in economic activity toward emerging economies, a redistribution of the world's middle classes, job polarization, and technology-fuel a move toward a very different and rapidly changing environment in which our graduates will eventually work and live. Higher education institutions must ensure that future graduates are well equipped to deal with the challenges that such a world will present to them. Attributes required of these graduates include those that are a necessary outcome of the internationalization of higher education, namely international awareness and intercultural competence. An added bonus would be the further development of so-called 2Ist century skills resulting from international mobility. These attributes will prepare our graduates more adequately for the future. Notwithstanding the numerous changes mentioned in this article, mankind's current activities are creating other challenges, such as global warming, the uneven availability and distribution of fresh water and food, a decline in biodiversity, and significant human migration as a result of conflict. If global economic changes are not driving our graduates' need to become internationally aware and interculturally effective, then these other challenges will certainly push this agenda forward. It is up to us to do what we can to pave the way and ensure that our graduates are prepared for the challenge. With such a massive agenda, one would have to ask whether we should not start with internationalization at the level of primary education, rather than introduce it only at the higher education level.

\section{Integrating Institutional Poli- cies and Leadership for 2Ist Century Internationalization}

\section{JOHN K. HUdzIK}

John K. Hudzik is NAFSA: Association of International Educators Senior Scholar for Internationalization at Michigan State University and Chair of the Scientific Committee of the Centre for Higher Education Internationalisation at Università Cattolica del Sacro Cuore, Milan, Italy.E-mail: hudzik@msu.edu.

$\mathrm{H}$ igher education is challenged to respond to a wide set of motivations and purposes for internationalization. There is pressure to mainstream student, staff, and faculty access to international perspective, involving all institutional core missions, and making ubiquitous who is expected to contribute and to be involved. In consequence, the need for deliberate and systemic institutional policies and leadership to support a more pervasive internationalization becomes necessary.

Motivations behind internationalization now encompass diverse purposes and intended outcomes, including access to global sources of cutting edge knowledge and partnerships, building cross-cultural knowledge and skills, developing an informed citizenry and workforce for a global environment, enhancing the global standing of the higher education institution, and promoting peace and mutual understanding, to name some.

The outcome expectations for internationalization have expanded beyond teaching and learning to also strengthen cross-border scholarship, research, and problem-solving service missions. The contemporary stakeholders of internationalization are diverse, each with particular outcome preferences (e.g., faculty for scholarship, career opportunities, and reputation; students and families for learning, jobs, and access to global opportunities; institutional leaders for access to funding and improved institutional reputation and capacity building; governments for workforce development and connections to the global market place). 